\title{
From hive minds to humans
}

Could an insect help us understand why some people are daredevils, or why others are overweight? Scientists who have sequenced and analysed the genome of the western honeybee Apis mellifera say it might. The sequence, released in this week's Nature (see page 931), is already aiding the young field of sociogenomics - the search for the genetic underpinnings of social life.

Researchers have shown some examples of how genes, the environment and behaviour can influence - and be influenced by - social interactions. Implanting one gene, for example, can change voles from promiscuous to monogamous (M. M. Lim et al. Nature 429, $754-757 ; 2004)$. And maternal care from rats helps pups to express genes that make them less susceptible to stress as adults (I. C. G. Weaver et al. Nature Neurosci. 7, 847-854; 2004).

But, besides its economicimportance (see 'Pollinators in peril'), the honeybee is the lodestone of social biology. "Everything they do is social," says Charles Whitfield, an entomologist and molecular biologist at the University of Illinois at Urbana-Champaign. The colony dynamic determines a beess diet, work and sex life, making bees ideal for studying some aspects of social biology, say scientists.

Researchers are also releasing a tool set for analysing the genome, including an improved microarray of honeybee genes and a list of DNA variations called single nucleotide polymorphisms. Scientists hope to use these tools to find the genetic causes of social traits - such as the bees' dance language and the division of labour in the hive. "We have so many behaviours in the bee for which we don't have any due about the mechanism," Whitfield says.

The genome is helping to reveal some of those mechanisms. For instance, there are 65 spots in the genome that seem to code for short

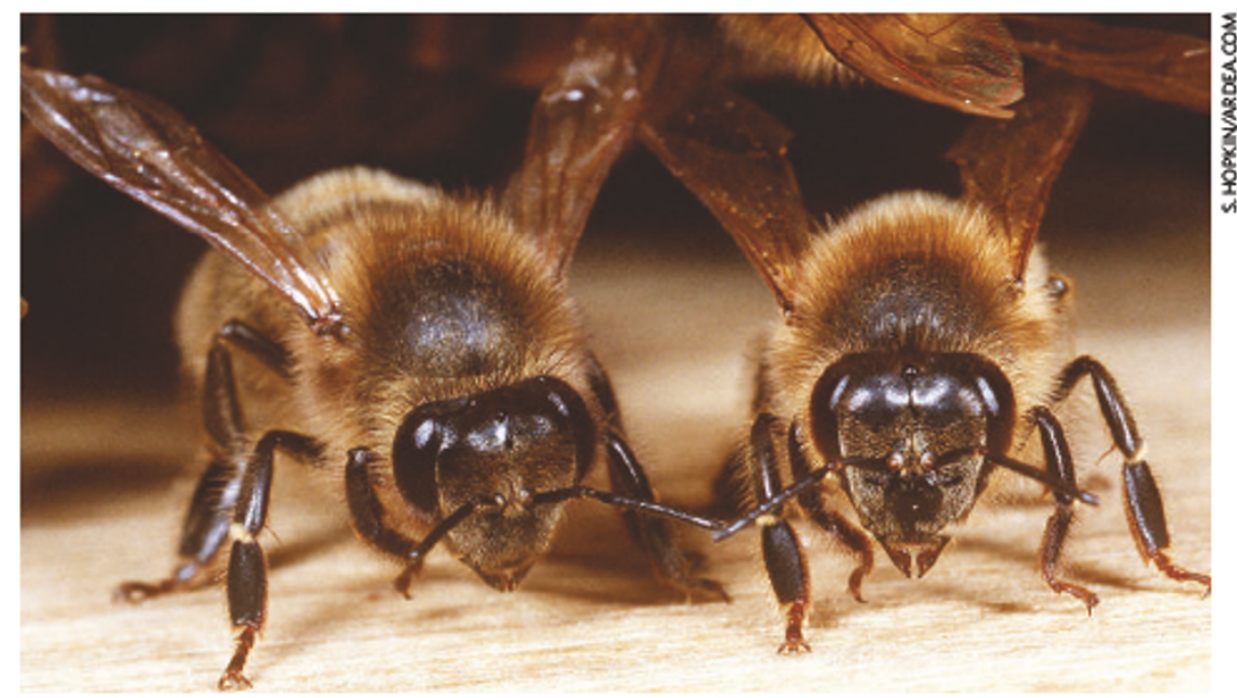

Work programme: a bee's job is determined by how its genes interact with its environment.

RNA molecules called microRNAs (miRNAs), molecular switches that can turn genes on or off. The researchers found that miRNA activity differs between bees doing different jobs. Such work starts to show how gene regulation gives the bee such a different lifestyle from, for example, the fruitfly, with which it shares many genes. "At the level of the brain, the parts list is pretty much the same as the fruitfly, yet there are these radical differences in behaviour and social organization," says George Weinstock, a genome biologist at Baylor College of Medicine in Houston, Texas. ${ }^{\alpha}$ That makes you think that regulation is probably more important than the parts list."

So, what does this have to do with people? Primate behaviour specialists say that there are parallels between honeybee and human socie-

\section{Pollinators in peril}

Honeybees aren't justbusy socialites. They're also crucial for agriculture, pollinating 90 major commercial crops in North America alone. But the honeybee and other pollinators are in danger. In a report issued on 18 October, the US National Academy of Sciences (NAS) found that pollinators such as bees, birds and bats are declining rapidly in North America. The report recommends that North Americans set up better monitoring systems for pollinators. Such systems are already in place in Europe, where scientists have documented the extinction of some pollinating species. Theagricultural beekeeping industry will probably ensure the honeybee's survival, butpopulations have still dropped by $30 \%$ over the past 20 years in North America, mainly due to the varroa mite. Scientists are working on breeding strains that are resistant to the mite, although the NAS report calls on industry to do more on this front. The genome sequence should help to speed the process up. ties. For instance, some individuals in each care for youngsters who aren't their offspring. But, cautions anthropologist Sarah Blaffer Hrdy of the University of California, Davis, honeybees and humans have many differences. "Anyone interested in the cognitive or emotional bases of cooperation should stick with other primates, or at the very least other social mammals," Hrdy says.

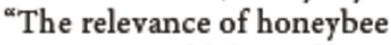
genomes would depend very much on the sort of questions one is asking."

Bee researchers say there could be links between human and beebehaviour. For instance, some bees seek out food sources, others wait and follow on. It's possible that scouts have the same sort of novelty-seeking genetic pathways that predispose some humans to become bungee jumpers. "One of the lessons of developmental biology is just how conserved gene function is in building complex phenotypes such as social behaviours, says Gene Robinson at the University of Illinois at Urbana-Champaign.

Some even see a link to human health. Worker bees make queens by feeding larvae a protein-rich substance called royal jelly. Understanding how the jelly reprogrammes genes might tell us more about how humans get fat, says molecular biologist Ryszard Maleszka at the Australian National University in Canberra. "Some of the insights we gain from following this protein family might be useful for probing a major problem in human society: obesity." Erika Check

See Editorial, page 884; News \& Views, page 919. 